\title{
Pharmacological Cognitive Enhancement and Cheapened Achievement: A New Dilemma
}

\author{
Emma C. Gordon (D) Lucy Dunn
}

Received: 10 August 2021 / Accepted: 25 September 2021 / Published online: 28 October 2021

(C) The Author(s) 2021

\begin{abstract}
Recent discussions of cognitive enhancement often note that drugs and technologies that improve cognitive performance may do so at the risk of "cheapening" our resulting cognitive achievements (e.g., Kass, Life, liberty and the defense of dignity: the challenge for bioethics, Encounter Books, San Francisco, 2004; Agar, Humanity's end: why we should reject radical enhancement, MIT Press, Cambridge, 2010; Sandel, The case against perfection. Harvard University Press, Cambridge, 2007; Sandel, The case against perfection: what's wrong with designer children, bionic athletes, and genetic engineering?". In: Holland (ed) Arguing about bioethics, Routledge, London, 2012; Harris in Bioethics 25:102-111, 2011). While there are several possible responses to this worry, we will highlight what we take to be one of the most promising —one which draws on a recent strand of thinking in social and virtue epistemology to construct an integrationist defence of cognitive enhancement. (e.g., Pritchard in Synthese 175:133-151, 2010; Palermos in Synthese 192:2955-2286, 2015; Clark in Synthese 192:3757$3375,2015)$. According to such a line, there isdespite initial appearances to the contrary-no
\end{abstract}

E. C. Gordon $(\varangle) \cdot$ L. Dunn

University of Glasgow, Flat 3/2, 6 Vinicombe Street, Hillhead, Glasgow G12 8BG, Scotland, UK

e-mail: Emma.Gordon@glasgow.ac.uk genuine tension between using enhancements to attain our goals and achieving these goals in a valuable way provided the relevant enhancement is appropriately integrated into the agent's cognitive architecture (in some suitably specified way). In this paper, however, we show that the kind of integration recommended by such views will likely come at a high cost. More specifically, we highlight a dilemma for users of pharmacological cognitive enhancement: they can (1) meet the conditions for cognitive integration (and on this basis attain valuable achievements) at the significant risk of dangerous dependency, or (2) remain free of such dependency while foregoing integration and the valuable achievements that such integration enables. After motivating and clarifying the import of this dilemma, we offer recommendations for how future cognitive enhancement research may offer potential routes for navigating past it.

Keywords Cognitive enhancement - Virtue epistemology $\cdot$ Cognitive integration $\cdot$ Achievement

\section{Introduction}

In contemporary bioethics, the human enhancement debate focuses on the ethical ramifications of improving ourselves through the use of increasingly sophisticated forms of medicine and 
technology. ${ }^{1}$ Some of this literature focuses on the possibility of enhancing our moral motivations and behaviour, ${ }^{2}$ while other work in this area focuses instead on the ways in which drugs might improve our emotional lives and our closest relationships. ${ }^{3}$ In this paper, our primary interest will be in cognitive enhancement, which involves improving or augmenting "internal or external information processing systems" [8]—in particular, we will consider one way in which cognitive enhancement might, counterintuitively, make us worse off. While there is lively debate about the conditions under which a given intervention constitutes an enhancement, we can think of cognitive enhancements generally as standing in contrast with therapeutic improvements-i.e., interventions that merely repair or treat some form of dysfunction. ${ }^{4}$ In other words, cognitive enhancements improve cognitive dispositions, performances, capacities and well-being in a way that goes beyond correcting pathology [2]. ${ }^{5}$

Of course, there are many widely accepted ways of improving cognitive capacities beyond the baselinefor example, taking part in study sessions, ingesting caffeine, and eating a healthy diet. However, the most interesting philosophical and ethical questions arise when we turn to interventions that might have more potent effects. Relevant current and possible future examples include brain computer interfaces (BCIs), ${ }^{6}$

\footnotetext{
${ }^{1}$ For example, see Clarke et al. [1] for a comprehensive overview of some of the most popular arguments for and against enhancement. In addition, see Juengst and Moseley [2] for a summary of key debates on human enhancement and for exploration of how the literature on enhancement relates to questions about the proper limits of healthcare.

${ }^{2}$ See Persson and Savulecsu [3, 4] for the most well-known work on moral enhancement.

3 For example, see Kraemer [5] for an in-depth exploration of whether induced emotions can be authentic and see Earp et al. [6, 7] for work on how we might safely and effectively use medical interventions to address relationship problems and help people detach from abusive relationships.

${ }^{4}$ See Gyngell and Selgeild [9] for a thorough inventory of the ways in which we might define "enhancement.".

5 Note that this improvement can involve improving existing capacities or generating new ones-so, a memory-boosting drug would be a cognitive enhancement, but so too would be an instance of genetic engineering that allows us to communicate telepathically.

${ }^{6}$ See e.g., He et al. [10] for a recent, general introduction to brain-computer interfaces and neural implants.
}

neural implants, genetic engineering, ${ }^{7}$ and pharmacological cognitive enhancements (hereafter, PCEs) ${ }^{8}$ drugs that improve our memory, focus, intelligence, and so on. Our central concern in this paper relates to the use of current and future PCEs (for example, modafinil, amphetamines, methylphenidate, and future drugs that likely use similar neurological mechanisms). However, as we'll later explore, our conclusion also has important and surprising ramifications for how we might think of some of these other forms of enhancement.

It's obvious why PCEs are alluring. On a personal level, an effective cognitive enhancement drug might provide an edge in one's career, make one a shaper conversationalist, and help one learn new skills at a faster rate (as well as perform old skills more effectively). ${ }^{9}$ Further, when we think about the well-being of society more broadly, there is good reason to suppose that PCEs could help to increase the speed at which important new developments emerge to improve quality of life-treatments for currently fatal diseases, for example.

However, bioconservative ethicists warn that we should be careful about blithely endorsing the use of such enhancements. There are many different reasons why one might adopt such a cautious line, ranging from concerns about exacerbating extant inequalities in society to suggestions that boosting intelligence may not promote well-being as much as one might think. ${ }^{10}$ Our focus in the following sections will be on one specific worry: that PCEs (and cognitive enhancement more broadly) make our achievements less valuable.

In Section 2, we'll explore exactly why one might plausibly worry that cognitive enhancement "cheapens" achievement, and look at how one particular response-the integrationist response-is especially

\footnotetext{
7 See e.g., Knot and Doudna [11] for an explanation of how CRISPR-Cas guides the future of genetic engineering in humans.

${ }^{8}$ See e.g., Maslen et al. [12] for an in-depth discussion of the ethics of PCE use.

9 See e.g., Gilleen et al. [13] and Linssen et al. [14] for some research on how both modafinil and methylphenidate might improve learning.

10 See e.g., Giubilini and Minerva [15] for consideration of proposals designed to combat enhancement-inducted inequality, and see Carter and Gordon [16] for some challenges to the assumption that cognitive enhancement promotes well-being.
} 
well-positioned to respond to this worry. In Sections 3 and 4, however, we will argue that despite the integrationist defence's initial promise, there is a serious and unexplored dilemma waiting in the wings for current and likely future pharmacological cognitive enhancement. This reveals the Problem of Cheapened Achievements to be more difficult to address than has been appreciated. More specifically, we will show why the integrationist defence leads to a situation in which having valuable enhanced achievements come at the price of significant drug dependency and an ongoing requirement to increase dosage (thereby also increasing the risk of serious health problems). As we'll see, whether the Problem of Cheapened Achievements can be resolved via an integrationist strategy depends very much on the future state of science and medicine.

\section{Cognitive Enhancement, Achievement and Integration}

\section{The Cheapened Achievements Problem}

Various bioconservative philosophers have advanced what we will called the cheapened achievements problem for cognitive enhancement. In some places, this is articulated as a worry about cheating (e.g., [17] or unfairness (e.g., [18]—-that, for example, students who take drugs like modafinil gain an unfair advantage over their peers, and are perhaps consequently less deserving of their resulting grades. However, there is a deeper worry at play-namely, that because cognitive enhancements can help us attain our cognitive goals faster and with less effort, the resulting achievements themselves are importantly less valuable than if the same goals were attained without enhancement. ${ }^{11}$ This means that even if considerations to do with competition and fairness are controlled for, we still have a reason to view cognitive enhancement in a negative light, if we care about having valuable achievements. The question at the heart of this sort of worry is neatly summarised by Bostrom and Sandberg [8], who ask: "If cognitive abilities are for sale, in the form of a pill

11 For one helpful way to characterise this argument, see Wang [, p. 123].19 or some external aid, would that reduce their value and make them less admirable?"

To illustrate the Cheapened Achievements Problem with a thought experiment, ${ }^{12}$ let's suppose that within the same 6-month period, two authors write excellent autobiographies based on their life experiences-and let's build into the case the fact that they will earn the same amount of money and reach the same level of critical acclaim. However, imagine that the first author completes her book using nothing more than coffee and willpower, while the second takes a daily dose of a powerful cognitive enhancement drug that improves her focus, reduces her need for sleep, boosts her memory and speeds up her problem-solving ability. One might be very tempted indeed to credit the second author-the cognitively enhanced authorwith a less significant achievement. And if we were to be told that this mirrored her own evaluation of her achievement, we would likely not be surprised. ${ }^{13}$

We can find many articulations of the cheapened achievements objection within the bioconservative literature. For example, Kass [21] holds that we lose something of significance when our cognitive functioning is enhanced via drugs or technologies. In particular, he argues, enhancement divorces performance from effort, giving us an "easy life" filled with "trivial" achievements that could otherwise have been valuable. Similarly, Carter and Pritchard [22] draw a useful analogy to computer games here: if we're trying to complete a difficult quest in a game and use a cheat code to super-charge our avatar and get rid of obstacles, it seems like the resulting success is less of an achievement that it would otherwise have been. ${ }^{14}$ Meanwhile, Harris [23] talks about the importance of our "freedom to fall", suggesting that great achievements that rely

\footnotetext{
12 Here, we adapt a case from Bradford [20], who focuses on works of fiction as achievements and does not discuss the potential impact of cognitive enhancement drugs.

${ }^{13}$ We are following precedent here in discussing the cheapened achievement objection in the context of enhancement rather than in the context of therapeutic improvement. For example, the intuition weakens significantly when we focus on cases where one relies on e.g., a pill in order to restore baseline levels of functioning. While the question of how the cheapened achievements objection applies in therapeutic cases is an interesting one, we are here going to be focusing on the objection in the context of the enhancement debate.

${ }^{14}$ For a recent and important reply to Carter and Pritchard, see Wang [19].
} 
heavily on enhancement technologies mean less due to a dramatically diminished likelihood of making errors. In a similar vein, Agar [24] suggests that our human fallibility with respect to achievements plays a significant role in the strong emotional response we have to success. Further, in Sandel [, pp. 25-26] we find the cheapened achievements objection framed in terms of credit and diminished agency-Sandel argues that the more one relies on enhancement for an achievement, the more "our admiration for the achievement shifts from the [agent] to their pharmacist." 25

The above kind of thinking is quite right, we might think, to suggest that we care when external factors influence our achievements. ${ }^{15}$ Indeed, even outside of the debate, we can see complementary claims being made. For example, in the literature on the nature and normativity of achievement, Gwen Bradford [27] argues that overcoming difficulty is a necessary component of achievements, and that exerting the kind of effort demanded by difficulty is responsible for their value. ${ }^{16}$ Indeed, perhaps it is considerations of difficulty and effort that explain the difference in our reactions to

\footnotetext{
15 It is worth noting that, to some extent, a kind of 'status quo bias' will almost inevitably play some role in framing our judgments about cheapened achievements. For example, some external artifacts that can enhance performance (reliance on a vitamins, eyeglasses that give us $20 / 20$ vision, etc.) are so common in a population that we don't think of them as enhancements, and likewise, even if we might be more inclined to were these not part of the status quo. Rather than to think that this point is indicative that the cheapened achievement intuition is somehow unreliable or biased in a way that is problematic, one may point out that such a bias will be inevitable given that any evaluation of achievements will inescapably be made against some status quo or another. For discussion on how the status quo can affect the sense in which we are inclined to 'relax' our judgments about our dependence on what is part of the status quo, see, e.g., Pritchard [26].

${ }^{16}$ It is worth noting that we often praise individuals for achievements that might seem effortless to the achiever.

17 As a referee points out, Bradford maintains that, while achievements are, in essence, competently caused difficult activities, the value of achievements is not limited to their being difficult, but also is sensitive to the extent to which the competent causation manifests rationality on the part of the agent. To the extent that this is right, then it might seem as though the following is true: an enhancement's undermining the extent to which a given achievement exhibits rationality on the part of the agent thereby undermines its value (Bradford op. cit., p. 122), We maintain that we should be sceptical, however, that Bradford's point about rationality is correct, at least, as a point about the value of achievements as such. Consider, for example, the case of an improvisational jazz musician -
}

the two authors in our example case above. ${ }^{17}$ In short: there is a compelling worry that when we make success easier, the resulting achievements are less valuable. Now, is there room for the cognitive enhancement advocate to give a convincing reply?

\section{The Bioconservative and Transhumanist Replies}

One reply to the Cheapened Achievements Problem is to simply bite the bullet when it comes to the alleged tension between cognitive enhancements and valuable achievements. Such a line would involve simply accepting that in order to maximise the value of our cognitive achievements, we should, ceteris paribus, maximally forego enhancements. Of course, in some cases, other overriding considerations will matter more than the value of an achievement. For example, if one is trying to cure some form of cancer and can do so faster with the help of a PCE and a brain computer interface, the diminished value of that achievement plausibly means very little compared to the resulting reduction in suffering and leap in scientific knowledge. However, as the bioconservative response maintains, from the perspective where what we care about is maximising the value of our achievements, we ought to give cognitive enhancements a wide berth. This, it would seem, is the view that thinkers along the lines of Kass and Sandel would adopt.

However, perhaps the bioconservative reply is too quick. Perhaps there's a better potential response to the cheapened achievements objection-one that allows us to take greater ownership of enhanced achievements, provided certain conditions are met.

A first pass at a more optimistic line here is found at the opposite end of the spectrum, at which the

\section{Footnote 17 (continued)}

one whose saxophone improvisation to accompanying piano and drums is intuitive, creative, and unrehearsed, and which is accompanied by an experience of 'flow' [28]. It is difficult to see how the source of the value of such an achievement lies in any expression of rationality on the part of the agent, and this is in particular the case given that conscious rational thinking tends to disrupt the experience of flow (see, e.g., [29]. Cases like improvisational jazz cast doubt on the generality of Bradford's claim that it is part of what sources the value of achievements as such is their connection to the exercise of rationality on the part of the agent. And this is so even if some achievements involve excellent exercises of rationality in virtue of which those particular achievements are valuable. 
transhumanist might argue that there's nothing problematic whatsoever about enhanced achievements-we are, as Andy Clark suggests in Natural Born Cyborgs [30], a species that has evolved to develop and use tools for augmenting our capacities, and continual pursuit of enhancement is just a mark of being human. However, this kind of reply to the Cheapened Achievements Problem involves effectively denying the prima facie plausible intuition underlying the problem-one that we saw (e.g., in the 'two writers' case) is widespread and compelling, and for which the transhumanist would arguably have to provide some kind of error theory. Put another way, the transhumanist recommends we avoid the problem, but in a way that would leave it mysterious why we were even drug into it in the first place.

A more moderate response would not quite bite the bullet, but would still account for the weight of the cheapened achievements objection. A promising way to develop such a moderate line maintains that the extent to which enhanced achievements are valuable is itself sensitive to facts about the relevant biotechnology and the agent's interaction with that biotechnology. The most promising version of that line of reply appears to be the integrationist reply to the Cheapened Achievements Problem, to which we'll now turn.

\section{The Integrationist Reply}

At this point in the dialectic, the defender of cognitive enhancement is in a position to make good use of recent work on cognitive achievements in social and virtue epistemology. The simple template structure of this reply first gives us a more detailed definition of achievement - that it is, borrowing from virtue epistemology (e.g., [31]), a success that is because of (i.e., primarily creditable to) ability. ${ }^{18}$ Such a proposal explains why, for example, an arrow shot by a skilled archer is not an achievement even if it hits the target, if it does so simply because of a fluke gust of wind, or because (say) the arrow had a 'target detecting' robot attached to it, which ensured it would hit the target. In such cases, the shot is successful in the sense that it attained the aim of hitting the target, but in such cases the shot is not successful

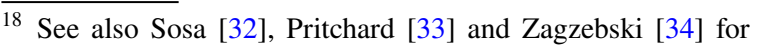
more details on this account of the nature of achievements, as well as for future nuances (e.g., how the account protects achievements-especially cognitive achievements-from being mere lucky successes).
}

because of the archer's skill, but because of something (e.g., wind, or the robot) external to their agency. ${ }^{19}$

With this simple "success because ability" structural view of achievement in play, then (for any given cognitive enhancement and achievement) we ought to be asking: is the relevant success sufficiently creditable to the person's ability? While the bioconservative would say 'no' and the transhumanist would 'say' yes-but in each case at the cost of incurring some theoretical baggage - the more nuanced integrationist line maintains that the matter of whether-or to what extent-using a given cognitive enhancement will cheapen an achievement will depend crucially on how we use the enhancement. As this line of thought goes, there are factors that can contribute to making cognitive enhancements (such as PCEs) suitably integrated into our cognitive architecture-into $u s$, in a sense-such that the resulting success is appropriately creditable to our abilities. And this is so even if there are some enhancements we depend on but which are not integrated in such a way.

The core idea submitted by the integrationist is that the less an enhancement is cognitively integrated into our cognitive architecture, the less the ensuing success we get by relying on the enhancement is actually creditable to our own cognitive abilities. On the other side of the coin, if the enhancement is integrated (enough), then there is no barrier to attributing the success to our abilities. ${ }^{20}$

\footnotetext{
${ }^{19}$ For discussion of the archery analogy in particular, see Sosa $[32,35]$.

${ }^{20}$ As noted previously, we are not assuming here (a la Bradford) that it is essential to achievements (as such) that a source of their value is an exercise of rationality on the part of the agent. That said, we would like to note that even if this claim is assumed, then there would be no barrier to accommodating it on an integrationist line. Assume, for some achievement $\mathrm{C}$, that $\mathrm{C}$ is valuable in part because of its connection to a manifestation of rationality on the part of the agent. Either an enhancement plays some role in facilitating that rationality or it does not. If it does not, then the enhancement is irrelevant to whatever contribution rationality makes to the value of the achievement. If it does, then-on the kind of integrationist line outlined here-we may consider whether the enhancement that impacts the value-adding rational exercise is suitably integrated (along the line sketched); if yes, then the enhancement is not a barrier to whatever value rational exercise adds to the given achievement. If no, then the integrationist line is able to get the right result, given that, on this supposition, the rational exercise at issue would not be suitably attributable to the agents' abilities given the role of the enhancement.
} 
The natural question at this juncture is this: what, then, is required for the kind of integration that matters for achievement? Here we find a range of answers in social epistemology. In a bit more detail, different philosophers have different explanations for what we needs to happen for some 'extra organismic' scaffolding (including pharmacological cognitive enhancements ${ }^{21}$ ) to become integrated in our cognitive architecture in such a way that the success we get by relying on it would be creditable to our abilities. Some suggested necessary conditions include the following (wherein, for ease of reference, ' $D$ ' represents the relevant drug):

The process awareness condition (e.g., [26]): D is integrated only if the subject forms an accurate view of how the wider processes that $\mathrm{D}$ uses is reliable.

The sensitivity condition (e.g., [36, 37]): D is integrated only if the subject is sensitive to different ways that $\mathrm{D}$ might malfunction.

The transparency condition (e.g., [38, 39]): D is integrated only if D plays the role it does in a way that is transparent, i.e., such that you don't critically scrutinise it.

While these are all different possible necessary conditions on a PCE's being suitably cognitively integrated, all of these authors share a point of commonality: that it takes time for these conditions to be met. As Pritchard [, p. 148] puts it, our intuition about whether certain cognitive achievements (e.g., knowledge) are creditable to the agent may be negative at first, but "as time goes on this intuition lessens." Meanwhile, as Heersmink [, p. 589] notes with respect to the transparency condition, novice users of a cognitive enhancement typically lack this transparency, and achieving it transparency "in most cases, needs training and may take a 26, 39considerable amount of time" (italics ours).

The thought that these conditions are better met over a lengthy period of enhancement use makes sense. For example, it stands to reason that the

\footnotetext{
21 This literature features a wide, inclusive treatment of "extraorganismic scaffolding", conceiving of it as any kind of "extra help" that aids performance but which is not innate-in this sense, cognitive enhancement drugs fall into the same category as computer chips, in that they are not part of your naturally endowed cognitive architecture.
}

transparency condition is better met the longer a drug is taken-when one begins taking a PCE, it is a novel experience that would likely prompt reflection on differences in thinking, in focus, and so on. However, as one becomes habituated to taking the relevant PCE, the normalisation of its use plausibly reduces the likelihood of one paying much attention to its normal functioning. Sheer duration of use over an extended period of time also clearly better positions one to satisfy both the process awareness condition and the sensitivity condition-the longer one takes a PCE, the better placed one is, with reference to accumulated track record evidence, to understand both how and when the PCE works, and to be alert if something goes wrong (e.g., picking up on the signs that something - such as taking a PCE with a large meal ${ }^{22}$ has slowed down the speed at the drug is absorbed and takes effect).

Accordingly, then, advocates of all three of the above potential necessary conditions on cognitive integration agree that the best way to meet these necessary conditions is to use the enhancement reliably over time. In sum, this consistent, repeated use is a key part of what is supposed to allow us to integrate a cognitive enhancement in a way that suffices for enhancement-facilitated successes to be valuable achievements.

For present purposes, we will set aside substantive critiques of the integrationist line itself, and accept that it does offer at least a prima facie plausible response to the Cheapened Achievements Problemespecially when compared to the other two main responses. Against that background, we want to focus on how research in medicine and pharmacology illuminates an unexplored dilemma for the integrationist strategy just sketched-one that reveals the Problem of Cheapened Achievements to be more difficult to address than has been appreciated (at least in some cases).

However, before proceeding, we want to clarify two additional points about the integrationist reply, in order to make explicit what it does and does not take for granted. For one thing, the integrationist line is assuming two ability-based claims about the structure of achievements and about their value-viz., that

\footnotetext{
${ }^{22}$ See e.g., Gilman et al. [40] for an elaboration of how one current PCE-Modafinil-is absorbed and excreted.
} 
(i) achievements are successes primarily creditable to ability; and that (ii) the source of the value of an achievement (over and above the value of a mere success) lies in part in the success's arising from ability.

While both assumptions (i) and (ii) are common in the literature on achievement in virtue epistemology [33, 41, 35], see also [42], they invite the following kind of rejoinder to assumption (i): no success is due entirely to an individual's ability, nor could it be rightly credited (entirely) to such an ability. This is because the fact that we have the dispositions, including abilities, we have is itself highly contingent upon other previous causes-including to a kind of egalitarian 'brute luck' ${ }^{23}$ (e.g., in the cognitive case, that we were born with particular kinds of cognitive faculties rather than others). ${ }^{24}$ Appreciation of this point, the rejoinder maintains, suggests it is mistaken to articulate achievements as successes primarily due to individuals themselves, ignoring the extent to which individuals' own capacities are always themselves beholden to fortune. In response to this concern, it's important to clarify the kind of 'template' characterisation of achievement that the integrationist is taking for granted, and which is standard in virtue epistemology. Crucially, primary credit can be understood in a strong, unrestricted sense (where ability would be contrasted on equal footing with all other factors that feature in a complete history of the relevant success), or in a more restricted sense that is indexed to causal-explanatory salience (Greco 2007, [41]). On the latter view-which is what we have in mindwhat the kind of attribution of success to ability that lines up with achievement requires is just that one's ability be (following here John Greco [41]) what is most explanatorily salient when giving an explanation of the relevant success-viz., as the most salient part of the causal explanation for the success. This articulation is compatible with there being a wide number

\footnotetext{
23 As an anonymous referee notes, it might well be that the radically diverse distribution pattern of cognitive capacities in a given population, patterns that are themselves beholden to luck, offer a moral justification for cognitive enhancement in the case of those who are unfortunate in this 'lottery'. We are sympathetic to this suggestion, though it goes beyond the scope of our aims here to make a moral case for justifying cognitive enhancement. For discussions on this issue, see Giubilini and Minerva [15] and Savulescu and Sandberg [43].

24 Thanks to an anonymous referee for suggesting we engage with this point.
}

of factors that play a role in the causal history of the relevant success.

A second point of clarification concerns assumption (ii), viz., that the source of the value of an achievement (over and above the value of a mere success) lies in part in the success's arising from ability. This is, we want to emphasise, a minimal assumption about what contributes to the value of achievement, and it is not meant to rule out possible alternative sources of the value of achievement whenever a success is primarily due to ability. For example, when a success is primarily due to ability, it might be that the achievement gains additional value in virtue of the level of exertion, or will-power exercised by the agent, and regardless of how highlevel her capacity is to perform. Theoretically, at least, there is no barrier to the possibility (e.g., in the more long-term future) that these other contributory sources of value to an achievement might themselves be susceptible to enhancement. ${ }^{25}$ For example, on the assumption that a success primarily due to ability is such that its value is (in some contexts) magnified by the addition of additional exertion or manifestation of will power, we could envision cases where that very will-power or effort capacity is itself subject to a kind of 'boost' via enhancement. We want to register that an integrationist line-given the assumptions it makes about achievement and its value-is not incompatible with countenancing such an idea, and it can diagnose achievement cases featuring a valuable exertion of will-power in a principled way. In short, on the integrationist line, an enhancement that directly impacts will power (in the way described above) is either itself going to be suitably integrated, or not; if yes, then the enhancement is not a barrier to whatever value willpower-exertion adds to the value of a given achievement. If no, then the integrationist line is able to get the right result, given that, on this supposition, the willpower's contribution would not be suitably creditable attributable to the agent.

\section{Cognitive Enhancement and the Risk of Dependence}

As it turns out, a potential worry for the integrationist reply to the Cheapened Achievements Problem lies waiting in the wings. In order to uncover the worry,

\footnotetext{
$\overline{25}$ Thanks to an anonymous referee for registering this point.
} 
it will be important to consider some of the costs of integration itself, in the case of pharmacological cognitive enhancements.

\section{Provisional PCEs: a Primer}

Adderall, Ritalin and Modafinil are most commonly discussed as viable examples or prototypes in the cognitive enhancement debate-consequently, we will call these "provisional PCEs". It is when we look at their theorised mechanism of action and effects that we begin to see specific risks they pose-risks that, we will argue, have a specific and important implication for integrationist replies to the Cheapened Achievements Problem.

Adderall is a mixed amphetamine salt, peak plasma concentrations of which peak approximately $3 \mathrm{~h}$ postingestion. ${ }^{26}$ Amphetamines are sympathomimetic noncatecholamines with CNS stimulant activity-their mechanism is poorly understood, but they are thought to limit reuptake of dopamine and noradrenaline to the presynaptic terminal. Crucially, amphetamines target the same receptors as the body's endogenous catecholamines, such as dopamine and noradrenaline. The chemical structure of amphetamines is very similar to those of the brain's monoamine neurotransmitters. Due to their sharing of a similar chemical structure, amphetamines are competitive substrates for transporters of the brain's own monoamine neurotransmitters, some of the most important being the transporter for noradrenaline (NET), dopamine (DAT) and serotonin or 5-HT (SERT). The ingestion of amphetamine accordingly causes changes in the levels of these neurons, and it is from the changing extracellular levels of these neurons that the behavioural and physical effects of amphetamines result. As powerful psychostimulants, they increase feelings of alertness, euphoria and wakefulness. They take primary effect centrally, however they also exert peripheral, autonomic side-effects, like sweating, nausea and tachycardia. Breathing rate increases, blood pressure increases and locomotor changes are seen. The mood changes are described as affecting feelings of 'novelty, arousal, anxiety [and] reward' [45].

\footnotetext{
$\overline{26}$ See e.g., Heal et al. [44] and Ferrucci et al. [45] for a pharmacological and clinical perspective on amphetamine.
}

Methylphenidate Hydrochloride (i.e., MPH) commonly known as Ritalin-is a psychostimulant with similar properties, with the immediate-release tablets reaching their maximum concentration in just under $2 \mathrm{~h}^{27}$ In its increase of extracellular dopamine levels, MPH amplifies task-specific signal-amplifying and noise-reducing effects of dopamine, meaning the subject taking MPH becomes less easily distractible and more focused and attentive-for example, Volkow et al. [46] determined that MPH-facilitated dopamine increases would likely increase the 'interest [the task] elicits' and therefore improve the subject's performance in that task. Peripheral side effects include agitation and aggression, autonomic effects such as increased heart rate, raised blood pressure and visual disturbances. Further, MPH should be used with caution in those with a psychiatric history, including previous psychosis or bipolar disorder, and in a small number of cases $(0.1 \%)$ it can elicit new psychosis or manic symptoms. Due to inter-individual variability in users of CNS stimulant drugs, it is currently 'difficult to predict' who will respond well to the drug [47]. Like amphetamine, the mechanism of action of this provisional PCE.

remains vague, but MPH is thought to stimulate dopamine release from the presynaptic vesicles, and inhibit dopamine reuptake back into presynaptic neurons-less selectively than amphetamine [48].

The third notable provisional PCE we will consider herein is modafinil (i.e., Provigil), a non-amphetamine type oral stimulant commonly used to treat narcolepsy (a brain condition that causes a person to fall asleep suddenly at inappropriate times). ${ }^{28}$ The maximum drug concentrations in the circulation are reached after 2-4 h, and steady states of modafinil are achieved after 2-4 days of taking the drug. Modafinil is best known for its promotion of alertness and reducing daytime sleepiness, but it also causes mood changes and alters perception and thinking. Again, as with both Adderall (i.e., mixed amphetamine salt) and Methylphenidate, the mechanism of action of Modafinil is not well understood-it appears to act similarly to the sympathomimetic agents, yet along

\footnotetext{
27 See e.g., Volkow et al. [46] for details on a PET-informed perspective on methylphenidate's mechanism of action.

${ }^{28}$ See e.g., Alacam et al. [49] for a more detailed account of modafinil's use and effectiveness.
} 
different mechanisms. Some studies have suggested that Modafinil action is dependent upon the dopamine transporter (DAT) and has weak interactions with dopamine, noradrenaline, orexin, histamine and serotonin receptors [50] - though it doesn't seem to promote spontaneous release of dopamine in the same way as amphetamine [50, 51].

\section{Why Provisional PCEs Come with a Burden of} Tolerance, Dependence and Abuse Potential

Drug tolerance results after continued, 'chronic' use (i.e., continued use over time) creating a dependence which in turn results in the 'progressive requirement to use higher drug doses to produce a given effect' (increasing the risk of side effects). ${ }^{29}$ Tolerancewhere regular increases in dose are required maintain effectiveness-also boosts the risk of dangerous side effects. In the case of provisional PCEs, the brain is not programmed to have consistently high levels of these extracellular neurotransmitters, and its homeostatic mechanisms cause it to try and counter the effects of the stimulant drugs. In order to adapt, the brain produces less neurotransmitters and expresses less neurotransmitter receptors, creating a hypofunctioning reward system that makes the effects of the drugs become less potent-prompting users to take more of the drug.

Dependence, meanwhile, encompasses two facets: physiological dependence and psychological dependence. ${ }^{30}$

Physiological dependence: an adaptive state that manifests itself by intense physical disturbances when the administration of a drug is suspended.

Psychological dependence: a condition in which

a drug produces a feeling of satisfaction and psychic drive that requires periodic or continuous administration of the drug to produce pleasure or to avoid discomfort.

Drug dependence is thought to begin with positive reinforcement [54] - the user experiences the euphoria and cognitive assonance of the stimulant, which

\footnotetext{
${ }^{29}$ Some authors see drug tolerance as the body's attempt to return to homeostasis, incorporating initial drug levels into its system to return to a type of pre-drug state (e.g., [52]).

30 This (conventional) distinction comes from Eddy et al. [53].
}

corresponds with an increased desire to continue their drug use. In the case of provisional PCEs such as those above, noradrenaline plays a role in increasing energy, and dopamine provides a pleasurable feeling of wellbeing. Later, negative reinforcement then joins the previous, positive reinforcement-after stopping drug intake for a period, the user experiences unpleasant withdrawal symptoms (e.g., dysphoria, decreased activity, lack of independent thought and increased drowsiness), and this prompts chronic use of the drug. Consequently, negative reinforcement is referred to as the "driving force of addiction" [55].

There is a particularly high abuse potential-a drug's ability to keep a person dependent on it with provisional PCEs and any drugs that act similarly. Once it is cleared, the 'up' effects of a provisional PCE will wear off, causing the user to feel relatively 'down'. The capacity of the drug to then correct the negative feeling its absence has left encourages the user to continue their use of the drug. The physical reasons for the abuse potential of provisional PCEs include the fact that they provide increased energy (via noradrenaline production) and a pleasurable feeling of well-being (via dopamine production). ${ }^{31}$ Meanwhile, some psychological reasons for this might include the confidence, self-esteem and day-to-day happiness that will likely wax and wane depending on whether one is experiencing the peak of cognitionsharpening effects of cognitive enhancement. ${ }^{32}$

Abuse potential is unsurprisingly related to addiction potential. ${ }^{33}$ Not everyone who uses-or even abuses-a substance becomes an "addict", and it is not completely clear in the literature as to how to spot someone likely to be predisposed to addictive vulnerability (for example, some studies discuss genetic factors (e.g., [57] whilst others e.g., [58] detail environmental or social problems). Regardless of individual

\footnotetext{
$\overline{31}$ See e.g., Gottlieb (2001).

32 Note that we here only scratch the surface of the psychological impact of PCEs and how that impact might contribute to psychological dependence. For example, there are possibly fruitful comparisons to be drawn between using cognitive enhancements and engaging in other "self-perfecting" activities (e.g., plastic surgery, diets, and other appearance enhancements). See e.g., Chatterjee [56] in particular for an exploration of parallels between what he calls "cosmetic neurology" and cosmetic surgery.

${ }^{33}$ Where we think of addiction roughly as an inability to stop a behaviour (often, but not always, something harmful).
} 
variances in susceptibility, Morton and Stock [59] note that clinicians should judge the potency of methylphenidate-for example-using descriptions of the effects elicited by better-known addictive substances, such as cocaine and methamphetamine (its more well-known, addictive relatives). And although modafinil is generally thought to be less worrying in this respect, some research (e.g., [55] suggests that it increases the rating scale of the Addiction Research Center Inventory (ARCI) "as much as amphetamine."

Sussman and Sussman [, pp. 4026-4030] provide an account of the five main components central to forming addictions, and it is easy to see how provisional PCEs could lead to meeting these conditions.601. Partaking in a certain course of action to fulfil motives (e.g., taking amphetamines to study more effectively).

2. Becoming preoccupied with that course of action (e.g., thinking about taking "smart drugs" more and more frequently),

3. Temporary satiation: a small time period which occurs after starting a habit where the "drug" or other tool does work to provide the user with feelings of fulfilment and satisfaction, without the appearance of cravings.

4. Loss of control: when a user wants to stop their use of the drug or other action but not being aware of how to control urges and prevent future use; 'the addictive behaviour may become increasingly more automatic' (e.g., one simply takes a nootropic as soon as they get up, or as soon as they sit down to take part in an academic task).

5. Suffering negative consequences (e.g., 'physical discomfort', like feeling agitated or withdrawn without amphetamines, or 'financial loss', after spending $£ 50$ a week (a rough approximation) on PCEs).

The potential for abuse (and possible addiction) is emphasized throughout the literature and should serve as a warning to clinicians. We also suggest that the changing function of these drugs from therapeutic interventions to enhancements carries the risk of aggravating abuse potential. And-perhaps most importantly-we have good reason to think that we can expect future PCEs to carry similar risks given the relevant underlying neurological mechanisms.
Most future PCEs are likely to also exert action upon noradrenaline and dopamine's extracellular concentrations, translating to increase cognitive capacities (e.g., alertness, focus, and processing speed)—and so come with the same risks as provisional PCEs.

Crucially, these concerns are just as likely to apply to future PCEs. Note that the provisional PCEs discussed herein are classed as such because of their neurological mechanisms. They all exert action upon noradrenaline and dopamine's extracellular concentrations, and through this specific means, they take effect in ways that translate into increasing our cognitive capacities, whether this is through increased alertness or wakefulness, or increased ability to focus. Now, Adderall, Ritalin and Modafinil are "back-door" $\mathrm{PCEs}^{34}$ - their current pharmaceutical indication is not to cognitively enhance healthy individuals, but to treat those with identified disorders (e.g., ADHD and narcolepsy). However, with their prominent presence in the human enhancement literature, it is fair to assume that future PCEs will be based on refined examples of these drugs. This means that we shall face the same problems as we do with the current provisional PCEs.

In sum, the important takeaway here, for our purposes, is this: provisional PCEs carry with them a burden of tolerance and dependence, as well as a high potential for abuse-and these are all worries that will apply equally to future drugs using similar mechanisms. We'll now explore how this create a serious difficulty for the integrationist reply to the Cheapened Achievements Problem.

\section{Cognitive Enhancement and Integration: A Dilemma}

The likely possibility of dependence and abuse (also correlated with higher likelihood of risks to health) seems to throw a new spanner in the works, in so far as we might appeal to an integrationist line as a response to the Problem of Cheapened Achievements. In particular, in light of the empirical results just canvassed, it looks like we're left with the following prima facie problematic options:

\footnotetext{
${ }^{34}$ Here we borrow the front-door/back-door distinction from Buchanan [61].
} 
Horn 1: Valuable achievements (due to appropriately integrated cognitive enhancements) at the risk of tolerance and dependence (and all the associated safety risks) due to consistent, long-term use.

Horn 2: Avoid tolerance/dependence through more sporadic use, but at the cost of integration and thereby of valuable achievements.

In the face of this dilemma, it looks like the three most salient lines of reply are as follows. Firstly, we could simply give up on any kind of integrationist reply — which, recall, pursues a middle ground to the Achievements Problem-and instead embrace one of the extremes (a strong bioconservative line or a transhumanist line). Problematically, however, neither of those other positions was promising. The second option on the table is to take horn 1 of the dilemma for the integrationist and preserve the value of enhancement-aided achievement at the cost of physical dependency (and its attendant risks). Meanwhile, the third option involves taking horn 2 of the dilemma - avoiding drug dependency (i.e., via only sporadic use) at the cost of the kind of integration that is plausibly needed to make sense of how the enhancement-aided success is an achievement to which we can credit you.

None of these options looks particularly appealing. So, does this mean that the Cheapened Achievements Problem is simply unresolvable? In spite of raising the above dilemma for the integrationist, we want to close by suggesting that it's too early to simply conclude that there's no satisfying response to the Cheapened Achievements Problem. More specifically, notice that one of the key contributors to the dilemma for the integrationist response is the fact that current pharmacological cognitive enhancements have some of the side effects they do-but this is only contingently so. It is not an essential feature of cognitive enhancements (pharmacological or otherwise) that they, for example, are detrimentally dependencyforming in the ways that current pharmacological enhancements are.

The foregoing observation offers us a new vantage point to realistically assess the Cheapened Achievements Problem. Rather than to either give up on the integrationist reply in favour of one of the 'nonstarter' responses, or to think that either horn 1 or horn 2 of the dilemma for the integrationist reply as (given currently technologies) clearly preferable to the other, we are in a position to view the lay of the land with a clear head. The realistic view here is that preserving the value of pharmacologically enhanced achievements might work in the future. This will depend on the future of medicine and technology - on whether pharmacological bioenhancements will be developed that can be used more than merely sporadically but without the relationship to dependency and other side effects that empirical research shows our current options have.

Meanwhile, if such pharmacological cognitive enhancement cannot be developed, then we still have the potential to have enhanced achievements that are primarily creditable to us (via integration)—so long as we are using technology-based enhancements like BCIs and implants, and we use these pieces of technology in the way required to meet the conditions for cognitive integration. ${ }^{35}$ To the extent that we value cognitive achievement, the foregoing also recommends that we direct cognitive enhancement research toward technological solutions as opposed to pharmacological interventions.

\section{Concluding Remarks}

We have explored several potential response to the common worry that cognitive enhancement may "cheapen" cognitive achievement. After dismissing the transhumanist and bioconservative responses as problematic in principle for different reasons, we highlighted the comparatively more promising integrationist defence - a line of argument that draws on social and virtue epistemology to respond to the Problem of Cheapened Achievements. However, in unpacking the temporal component of this defence and considering the risks associated with cognitive enhancement drugs that share a particular set of neural mechanisms, we saw that the integrationist is faced with a dilemma. They can risk dependency and addiction while gaining credit for their cognitive achievements (and thereby retaining their value), or they can avoid such physical and psychological risks

\footnotetext{
$\overline{35}$ It is difficult to predict how far away we are presently from such technologies; that said, recent and rapid advances in deep neural networks in medicine give some cause for optimism.
} 
but forego integration and the valuable achievements it brings. ${ }^{36}$

Open Access This article is licensed under a Creative Commons Attribution 4.0 International License, which permits use, sharing, adaptation, distribution and reproduction in any medium or format, as long as you give appropriate credit to the original author(s) and the source, provide a link to the Creative Commons licence, and indicate if changes were made. The images or other third party material in this article are included in the article's Creative Commons licence, unless indicated otherwise in a credit line to the material. If material is not included in the article's Creative Commons licence and your intended use is not permitted by statutory regulation or exceeds the permitted use, you will need to obtain permission directly from the copyright holder. To view a copy of this licence, visit http://creativecommons.org/licenses/by/4.0/.

\section{References}

1. Clarke, Steve, Julian Savulescu, Tony Coady, Alberto Giubilini, and Sagar Sanyal, eds. 2016. The Ethics of human enhancement: Understanding the debate. Oxford: Oxford University Press.

2. Juengst, Eric. and Daniel Moseley. 2016. Human enhancement. In The Stanford encyclopedia of philosophy, E Zalta ed.

3. Persson, Ingmar, and Julian Savulescu. 2008. The perils of cognitive enhancement and the urgent imperative to enhance the moral character of humanity. Journal of Applied Philosophy 25 (3): 162-177.

4. Persson, Ingmar, and Julian Savulescu. 2012. Unfit for the future: The need for moral enhancement. Oxford: Oxford University Press.

5. Kraemer, Felicitas. 2011. Authenticity anyone? The enhancement of emotions via neuro-psychopharmacology. Neuroethics 4 (1): 51-64.

6. Earp, Brian, Anders Sandberg, and Julian Savulescu. 2012. Natural selection, childrearing, and the ethics of marriage (and divorce): Building a case for the neuroenhancement of human relationships. Philosophy and Technology 25 (4): 561-587.

7. Earp, Brian, Olga Wudarczyk, Anders Sandberg, and Julian Savulescu. 2013. If I could just stop loving you: Anti-love biotechnology and the ethics of a chemical breakup. American Journal of Bioethics 13 (11): 3-17.

\footnotetext{
36 The authors would like to thank the editor and two anonymous referees at Neuroethics for helpful feedback. Gordon acknowledges that this paper was written as part of the Leverhulme-funded 'A Virtue Epistemology of Trust' (\#RPG-2019302) project, which is hosted by the University of Glasgow's COGITO Epistemology Research Centre, and would like to thank the Leverhulme Trust for supporting this research. Gordon would also like to thank an audience at Kansai University's 'Striving for Perfection' conference (February 2021).
}

8. Bostrom, Nick, and Anders Sandberg. 2009. Cognitive enhancement: Methods, ethics, regulatory challenges. Science and Engineering Ethics 15 (3): 311-341.

9. Gyngell, Chris., and Michael J. Seigeld. 2016. Human enhancement: Conceptual clarity and moral significance. In The ethics of human enhancement: understanding the debate, S Clarke, J Savulescu, CAJ Coady, A Giubilini \& S Sanyal, eds, pp. 111-126.

10. He, B., H. Yuan, J. Meng, and S. Gao. 2020. Brain-computer interfaces. In Neural engineering, ed. B. He. Cham: Springer.

11. Knott, Gavin J., and Jennifer A. Doudna. 2018. CRISPRcas guides the future of genetic engineering. Science 361 (6405): 866-869.

12. Maslen, Hannah, Nadira Faulmüller, and Julian Savulescu. 2014. Pharmacological cognitive enhancement-how neuroscientific research could advance ethical debate. Frontiers and Systems Neuroscience. https://doi.org/10.3389/fnsys. 2014.00107.

13. Gilleen, J., P.G. Michalopoulou, A. Reichenberg, R. Drake, T. Wykes, S.W. Lewis, and S. Kapur. 2014. Modafinil combined with cognitive training is associated with improved learning in healthy volunteers - a randomised controlled trial. European Neuropsychopharmacology 24 (4): 529-539.

14. Linssen, A.M.W., A. Sambeth, E.F.P.M. Vuurman, and W.J. Riedel. 2014. Cognitive effects of methylphenidate in healthy volunteers: A review of single dose studies. International Journal of Neuropsychopharmacology 17 (60): 961-977.

15. Giubilini, Alberto, and Francesca Minerva. 2019. Enhancing equality. The Journal of Medicine and Philosophy: A Forum for Bioethics and Philosophy of Medicine 44 (3): 335-354.

16. Carter, J. Adam., and Emma Gordon. 2013. Intelligence, well-being and procreative beneficence. Journal of Applied Philosophy 30 (2): 122-135.

17. Schermer, Maartje. 2008. Enhancements, easy shortcuts, and the richness of human activities. Bioethics 22 (7): 355-363.

18. Faber, Nadira, Julian Savulescu, and Thomas Douglas. 2016. Why is cognitive enhancement deemed unacceptable? The role of fairness, deservingness and hollow achievements. Frontiers in Psychology 7: 232.

19. Wang, Ju. 2021. Cognitive enhancement and the value of cognitive achievement. Journal of Applied Philosophy 38: 121-135.

20. Bradford, Gwen. 2015. Achievement. Oxford: Oxford University Press.

21. Kass, Leon R. 2004. Life, liberty and the defense of dignity: The challenge for bioethics. San Francisco: Encounter Books.

22. Carter, J. Adam., and Duncan Pritchard. 2017. Epistemology of cognitive enhancement. The Journal of Medicine and Philosophy 34: 85-88.

23. Harris, John. 2011. Moral enhancement and freedom. Bioethics 25 (2): 102-111.

24. Agar, Nicholas. 2010. Humanity's end: Why we should reject radical enhancement. Cambridge: MIT Press.

25. Sandel, Michael J. 2012. The case against perfection: what's wrong with designer children, bionic athletes, and 
genetic engineering?. In Arguing about bioethics, ed. S Holland. London: Routledge.

26. Pritchard, Duncan. 2010. Cognitive ability and the extended cognition thesis. Synthese 175 (1): 133-151.

27. Bradford, Gwen. 2013. The value of achievement. Pacific Philosophical Quarterly 94 (2): 204-224.

28. Hytonen-Ng, Elina. 2016. Experiencing "flow" in jazz performance, 2016. London: Routledge.

29. Nakamura, Jeanne, and Mihaly Csikszentmihalyi. 2014. The concept of flow. In Flow and the foundations of positive psychology, 239-263. Dordrecht: Springer.

30. Clark, Andy. 2003. Natural Born Cyborgs. Oxford: Oxford University Press.

31. Greco, John. 2012. A (different) virtue epistemology. Philosophy and Phenomenological Research 85: 1-26.

32. Sosa, Ernest. 2015. Judgement and agency. Oxford: Oxford University Press.

33. Pritchard, Duncan. 2012. Anti-luck virtue epistemology. Journal of Philosophy 109: 247-279.

34. Zagzebski, Linda. 1996. Virtues of the mind: An inquiry into the nature of virtue and the ethical foundations of knowledge. Cambridge: Cambridge University Press.

35. Sosa, Ernest. 2007. A Virtue Epistemology: Apt Belief and Reflective Knowledge. Oxford: Oxford University Press.

36. Palermos, Spyridon Orestis. 2015. Active externalism, virtue reliabilism and scientific knowledge. Synthese 192 (9): 2955-2986.

37. Carter, J.A., and D. Pritchard. 2019. Extended Entitlement. In New Essays on Entitlement, ed. P. Graham and N. Pedersen. Oxford: Oxford University Press.

38. Clark, Andy. 2015. What "extended me" knows. Synthese 192 (11): 3757-3775.

39. Heersmink, Richard. 2015. Dimensions of integration in embedded and extended cognitive systems. Phenomenology and the Cognitive Sciences 13 (3): 577-598.

40. Gilman, Alfred Goodman, Joel G. Hardman, and Lee E. Limbird. 2001. Goodman \& Gilman's the pharmacological basis of therapeutics. New York: McGraw-Hill.

41. Greco, John. 2010. Achieving Knowledge: A Virtue-Theoretic Account of Epistemic Normativity. Cambridge: Cambridge University Press.

42. Feinberg, Joel. 1970. Doing \& deserving; Essays in the theory of responsibility. Princeton: Princeton University Press.

43. Savulescu, J., and A. Sandberg. 2008. Neuroenhancement of love and marriage: The chemicals between us. Neuroethics 1 (1): 31-44.

44. Heal, D., S. Smith, J. Gosden, and D. Nutt. 2013. Amphetamine, past and present-a pharmacological and clinical perspective. Journal of Psychopharmacology 27 (6): 479-496.

45. Ferrucci, M., Limanaqi, F., Ryskalin, L., Biagoni, F., Busceti, C., Fornai, F. 2019. The effects of amphetamine and methamphetamine on the release of norepinephrine, dopamine and acetylcholine from the brainstem reticular formation. Frontiers in Neuroanatomy 13.

46. Volkow, N.D., J.S. Fowler, G.J. Wang, and R.Z. Goldstein. 2002. Role of dopamine, the frontal cortex and memory circuits in drug addiction: insight from imaging studies. Neurobiology of Learning and Memory 78 (3): 610-624.
47. Kimko, H.C., J.T. Cross, and D.R. Abernethy. 1999. Pharmacokinetics and Clinical Effectiveness of Methylphenidate. Clinical Pharmacokinetics 37: 457-470.

48. Scahill, Lawrence, Deirdre Carroll, and Kathleen Burke. 1999. Methylphenidate: Mechanism of Action and Clinical Update. Journal of Child and Adolescent Psychiatric Nursing 17 (2): 85-86.

49. Alacam, H., O. Basay, S. Tumkaya, M. Mart, and G. Kar. 2018. Modafinil dependence: A case with attention-deficit/hyperactivity disorder. Psychiatry Investigation 15 (4): 424-427.

50. Gerrard, P., and R. Malcolm. 2007. Mechanisms of modafinil: A review of current research. Neuropsychiatric disease and treatment 3 (3): 349-364.

51. Simon, P., C. Hémet, C. Ramassamy, and J. Costentin. 1995. Non-amphetaminic mechanism of stimulant locomotor effect of modafinil in mice. European Neuropsychopharmacology 5 (4): 509-514.

52. Koob, G., and F. Bloom. 1998. Cellular and molecular mechanisms of drug dependence. Science 242 (4879): 715-723.

53. Eddy, Nathan B., H. Halbach, Harris Isbell, and Maurice H. Seevers. 1965. Drug dependence: Its significance and characteristics. Bulletin of the World Health Organization 32 (5): 721-733.

54. Kreek, M., and G. Koob. 1998. Drug dependence: stress and dysregulation of brain reward pathways. Drug and Alcohol Dependence 51 (1-2): 23-47.

55. Kollins, S., E. MacDonald, and C. Rush. 2001. Assessing the abuse potential of methylphenidate in nonhuman and human subjects: A review. Pharmacology Biochemistry and Behavior. 68 (3): 611-627.

56. Chatterjee, Anjan. 2007. Cosmetic neurology and cosmetic surgery: Parallels, predictions, and challenges. Cambridge Quarterly of Healthcare Ethics 16: 129-137.

57. Kreek, M., D. Nielsen, E. Butelman, and K. LaForge. 2005. Genetic influences on impulsivity, risk taking, stress responsivity and vulnerability to drug abuse and addiction. Nature Neuroscience 8 (11): 1450-1457.

58. Hellman, M., M. Majamäki, S. Rolando, M. Bujalski, and P. Lemmens. 2015. What causes addiction problems? Environmental, biological and constitutional explanations in press portrayals from four European welfare societies. Substance Use \& Misuse 50 (4): 419-438.

59. Morton, W., and G. Stock. 2000. Methylphenidate abuse and psychiatric side effects. The Primary Care Companion to The Journal of Clinical Psychiatry. 02 (05): 159-164.

60. Sussman, S., and A. Sussman. 2011. Considering the definition of addiction. International Journal of Environmental Research and Public Health 8 (10): 4025-4038.

61. Buchanan, Allen. 2017. Better than human: The promises and perils of biomedical enhancement. Oxford: Oxford University Press.

Publisher's Note Springer Nature remains neutral with regard to jurisdictional claims in published maps and institutional affiliations. 